\title{
Ultraviolet Radiation and Salinity-Induced Physiological Changes and Scytonemin Induction in Cyanobacteria Isolated from Diverse Habitats
}

\author{
Jainendra Pathak ${ }^{1}\left(\mathbb{D}\right.$, Deepak Kumar ${ }^{2(\mathbb{D})}$, Deepak K. Singh ${ }^{3(\mathbb{D}}$, Haseen Ahmed ${ }^{4} \mathbb{(}$, Vinod K. \\ Kannaujiya $^{5 \text { (i) , Rajeshwar P. Sinha }}{ }^{2, *(D)}$ \\ 1 Department of Botany, Pt. Jawaharlal Nehru College (Affiliated to Bundelkhand University, Jhansi), Banda-210001, India \\ 2 Laboratory of Photobiology and Molecular Microbiology, Centre of Advanced Study in Botany, Institute of Science, \\ Banaras Hindu University, Varanasi-221005, India \\ 3 Department of Botany, Acharya Narendra Deo Kisan P. G. College, Gonda-271313, India \\ 4 Department of Botany, Government Girls P.G. College, Satna-485001, India \\ 5 Department of Botany, MMV, Banaras Hindu University, Varanasi-221005, India \\ * Correspondence: rpsinhabhu@gmail.com (R.P.S.);
}

Scopus Author ID 35485458700

Received: 2.06.2021; Revised: 8.07.2021; Accepted: 11.07.2021; Published: 10.08.2021

\begin{abstract}
Enhanced ultraviolet radiation (UVR) in the atmosphere and increased salinity of soils and water adversely affect photoautotrophs' productivity. Several researchers have focussed on the use of non-arable or brackish environments for growing strains suitable for the production of value-added products along with biofuels. In this regard, cyanobacteria serve as good model organisms as they can survive and sustain themselves in habitats characterized by high UV influx and changing salinities. Thus, these photoautotrophs can help understand the complex physiological processes and adaptations occurring in higher plants growing in stressed environments of salinity and UVR. In the present investigation, cumulative effects of salinity ( $\mathrm{NaCl}: 50,100$, and $200 \mathrm{mM}$ ), photosynthetically active radiation (PAR), and UVR have been studied in terms of the reactive oxygen species (ROS) generation, total protein content, phycobiliproteins profile, and induction of scytoneminin in the two cyanobacteria isolated from different habitats. Production of ROS increased after PAR+UV-A+UV-B, PAR+UV-A, and PAR exposure, and maximum generation occurred in the samples treated with $200 \mathrm{mM} \mathrm{NaCl}$. Total protein content and phycobiliproteins profile was severely affected by these stresses. The maximum induction of scytonemin occurred in the cultures with $200 \mathrm{mM}$ of $\mathrm{NaCl}$ and PAR+UV-A+UV-B exposure for $72 \mathrm{~h}$. Our results indicate that Scytonema sp. could serve as a potential candidate for bioremediation of saline soils along with the production of value-added metabolite scytonemin.
\end{abstract}

Keywords: cyanobacteria; phycobiliproteins; reactive oxygen species; salinity; scytonemin; ultraviolet radiation

(C) 2021 by the authors. This article is an open-access article distributed under the terms and conditions of the Creative Commons Attribution (CC BY) license (https://creativecommons.org/licenses/by/4.0/).

\section{Introduction}

Cyanobacteria, the prokaryotic photoautotrophs found in almost every plausible habitat on Earth, originated in the Precambrian era during the ozone-less environment. As a result of continued thinning of the stratospheric ozone layer from the atmospheric pollutants released anthropogenically, the influx of ultraviolet radiation (UVR) on the Earth's surface has increased, exposing these photoautotrophs to the lethal doses of UVR in their natural habitats $[1,2]$. UV-B is absorbed by biomolecules such as proteins, nucleic acids, and lipids and 
ultimately results in harmful effects on the biological systems [3-7]. UVR affects several physiological and metabolic processes in cyanobacteria, such as growth, survival, pigmentation, motility, photosynthetic oxygen production, $\mathrm{N}_{2}$ uptake, $\mathrm{CO}_{2}$ uptake, and phycobiliprotein (PBP) composition [6, 8-12]. However, cyanobacteria have developed several strategies for their protection and biosynthesis of UV-screening pigment scytonemin is one of the several defense mechanisms evolved by cyanobacteria to counteract the damaging effects of UVR [13-21]. Photoprotective metabolite scytonemin significantly absorbs lethal UVR $[22,23]$.

Salinity is a crucial historical factor that influences the life span of agricultural systems. Cyanobacteria have been used in reclaiming saline soils due to their salt stress tolerance [2426]. The extant cyanobacteria serve as good model organisms for studying the molecular mechanism of salt tolerance in higher plants and their physiology [27]. Cyanobacteria can be used as a tool for reclamation of Usar soils as they convert the $\mathrm{Na}^{+}$clay to $\mathrm{Ca}^{2+}$ clay by conserving the organic $\mathrm{C}, \mathrm{N}$, and $\mathrm{P}$ as well as moisture and forming a thick stratum on the soil surface [28]. They secrete oxalic acid and solubilize nutrients from insoluble carbonate nodules. Hence, they improve the physicochemical quality of sodic soils, such as soil aggregation, by lowering the electrical, hydraulic conductivity, and $\mathrm{pH}$ [29]. The physiological basis of the salt tolerance of cyanobacteria has been studied to some extent but is still not fully understood $[6,21]$.

During stressful conditions, toxic reactive oxygen species (ROS) production occurs in the cells [30,31]. Salinity stress increases ROS generation, which affects photosynthetic pigments and important biomolecules such as nucleic acids and proteins [32,33]. In salttolerant cyanobacteria such as Euhalothece sp. and Synechocystis PCC 6803, salt-induced effects have been studied extensively [34-36]. In cyanobacteria, in response to stressful conditions, the function and composition of PBPs also get changed [37]. Several physiobiochemical processes such as photosynthesis, nitrogen assimilation, lipid metabolism, and ion homeostasis are adversely affected by salinity [27]. Due to salt stress, a decrease in phycocyanin (PC) content has been observed, thereby interrupting the transfer of energy from PBPs to the PS-II reaction center[38-41]. In Spirulina platensis decrease in the transfer of energy from allophycocyanin to PSII was observed on the addition of $\mathrm{NaNO}_{3}, \mathrm{NaCl}$, and $\mathrm{NaHCO}_{3}$ [42]. In several cyanobacteria, UVR causes disassembly of phycobilisomal complex and a decrease in the PBP content [10]. Due to their water-soluble property, PBPs seem to be the most sensitive pigments to UVR [43]. It was found that the accessory pigment PC ( $\lambda_{\max } 620$ $\mathrm{nm})$ bleached more rapidly in comparison to carotenoids $\left(\lambda_{\max } 485 \mathrm{~nm}\right)$ or Chl $a\left(\lambda_{\max } 437\right.$ and $672 \mathrm{~nm}$ ), suggesting that the primary target of UVR are proteinaceous pigments [44-45].

Scytonemin has been isolated from more than 300 cyanobacteria and is a lipid-soluble, highly stable, yellow-brown pigment present in their extracellular polysaccharide sheaths [18]. It is composed of a dimer of phenolic and indolic subunits linked through an olefinic carbon atom, which makes it unique among different natural products [18, 22]. Scytonemin biosynthesis is affected under different stress conditions such as oxidative stress, UVR, osmotic stress, and heat [46]. Its production was significantly influenced by changes in salt concentrations, and different salinity levels also affected the formation of different forms of scytonemin, as observed in Lyngbya aestuarii [47]. Besides photoprotection, scytonemin performs multiple functions, and several workers have established its biotechnological utility [48-50]. In cyanobacteria, induction and biosynthesis of the pigment scytonemin could be one of the several strategies of survival adopted by these organisms during salinity stress. 
Regulation of scytonemin induction occurs via a complex stress response pathway as multiple environmental signals influence its biosynthesis. Much study has been done on the effect of light quality on scytonemin biosynthesis [51-53]. Production of scytonemin in sheathed cyanobacteria constitutes a crucial adaptive strategy of protection against lethal UVR [54,55]. The impact of other stresses such as salinity on its synthesis still needs thorough study. Hence, in this study, we have attempted to investigate the cumulative effects of salinity and UVR on some physiological processes in the two cyanobacteria isolated from different habitats and their effects on scytonemin biosynthesis.

\section{Materials and Methods}

\subsection{Experimental organisms and growth conditions.}

For experiments, laboratory-grown cultures of Nostoc sp. strain HKAR-2, isolated from the hot springs of Rajgir, Bihar, India $\left(25^{\circ} 2^{\prime} 0^{\prime \prime} \mathrm{N}, 85^{\circ} 25^{\prime} 0^{\prime \prime} \mathrm{E}\right)$ [56], and Scytonema sp. isolated from the rooftop of Department of Botany, Banaras Hindu University, Varanasi, India, $\left(25^{\circ} 15^{\prime} 51.89^{\prime \prime} \mathrm{N}, 82^{\circ} 59^{\prime} 42.05^{\prime \prime} \mathrm{E}\right)$ were used. Standard taxonomic keys and monographs were used for identification of both the cyanobacteria [57-58], and Nostoc sp. strain HKAR-2 (accession number: FJ939126) was previously identified by 16SrRNA gene sequencing [56]. Scytonema sp. is filamentous, sheathed, and heterocystous cyanobacterium, which grows autotrophically and has pseudo branching in its filaments. Nostoc sp. strain HKAR-2 is characterized by a frothy thallus, circinate, gelatinous, non-sheathed trichomes with ellipsoidal cells and is a heterocyst-forming cyanobacterium. Standard microbiological techniques were used for culturing cyanobacteria [59]. BG-11 medium [60] without nitrogen supplementation was used for growing the axenic cultures of the cyanobacteria at $20 \pm 2{ }^{\circ} \mathrm{C}$ with a $14 / 10$-h light/dark cycle illuminated with cool white fluorescent tubes (PhilipsTL $40 \mathrm{~W} / 54$, India) having an irradiance of $12 \pm 2 \mathrm{Wm}^{-2}$ at the surface of the vessels. The subculturing of cyanobacterial cultures was done at regular intervals, and the cultures were hand-shaken five times daily to avoid contamination. Log phase cultures having an initial optical density of 0.5 at $750 \mathrm{~nm}$ were used for performing experiments.

\subsection{Set up for UV irradiation and salinity stress.}

A UV-chamber was used for exposing the cyanobacterial samples to artificial UVR in open glass Petri dishes which was fitted with Osram L 36 W/ 32 Lumilux de luxe warm white and radium NL 36 W/26 Universal white tubes (Osram, Munich, Germany) for photosynthetically active radiation (PAR), ultraviolet-B TL $40 \mathrm{~W} / 12$ fluorescence tubes (Cat No. G15T8E, Sankyo Denki, Japan), emitting its main output at $312 \mathrm{~nm}$ and ultraviolet-A TL $15 \mathrm{~W}$ fluorescence tubes (Philips ACITINIC BL 15W UVA tubes), emitting its main output at $365 \mathrm{~nm}$ for UVR treatment. To get the desired radiation intensity, the distance of the cyanobacterial sample was adjusted accordingly from the PAR and UV-tubes in the chamber and cultures were simultaneously irradiated with PAR during UV treatment. Homogeneous cultures $(800 \mathrm{~mL})$ of cyanobacteria with varying concentrations of $\mathrm{NaCl}(50,100$, and 200 $\mathrm{mM}$ ) in the culture media were exposed to UVR and PAR in sterile open Petri dishes for the time intervals of 12, 24, 36, 48, 60 and $72 \mathrm{~h}$. Petri dishes containing cyanobacterial samples were covered with 395, 320, and $295 \mathrm{~nm}$ cut-off filter foils (Ultraphan; Digefra, Munich, Germany) to ensure PAR, PAR+UV-A (PA), and PAR+UV-A+UV-B (PAB) exposure, respectively. The intensities of UV-B, UV-A, and PAR were 0.56, 6.5, and $14 \pm 2 \mathrm{Wm}^{-2}$, 
respectively. During the entire duration of exposure, the temperature was maintained at $25 \pm 2$ ${ }^{\circ} \mathrm{C}$. An equal amount of cells were removed from each Petri dish after 12, 24, 36, 48, 60, and $72 \mathrm{~h}$ of continuous exposure and analyzed for physiological parameters such as ROS formation, total protein content, PBPs profile, and scytonemin induction. To avoid self-shading of the cells and heating effects, the cultures were shaken at regular intervals during the exposure. Cyanobacterial samples irradiated with PAR served as control.

\subsection{Detection of in vivo ROS generation using 2',7'-dichlorodihydrofluorescien diacetate} (DCFH-DA).

For detection of in vivo generation of ROS, DCFH-DA was used, which gets oxidized to 2',7'-dichlorofluorescien (DCF) in vivo and is highly fluorescent [61-64]. After the desired duration of treatments, $10 \mu \mathrm{L}$ of DCFH-DA (final concentration $5 \mu \mathrm{M}$ ) solubilized in ethanol was added to the cyanobacterial cultures followed by incubation of samples in the dark on a shaker at room temperature for $1 \mathrm{~h}$. Thereafter, the fluorescence spectroscopy of cyanobacterial samples was carried out to determine DCF with $485 \mathrm{~nm}$ as an excitation wavelength and an emission band between 500-600 $\mathrm{nm}$.

\subsection{Protein estimation.}

The method of Lowry et al. [65] was followed for determining the protein content of the cyanobacterial samples.

\subsection{Extraction of phycobiliproteins.}

The PBPs were extracted from treated cyanobacterial samples by the method of Sinha et al. [44]. Cells were harvested by centrifugation (1500×g for $10 \mathrm{~min}$ ) at room temperature and were washed twice with $0.75 \mathrm{M}$ potassium phosphate buffer $(\mathrm{pH} 7.0)$. The cells were then resuspended in a minimum amount of the same buffer, and $1 \mathrm{mM}$ phenylmethanesulfonylfluoride (PMSF), 5\% (w/v) sucrose, and 10\% (w/v) EDTA was added. With the help of mortar and pestle, cells were disrupted, and repeated cycles of freeze-thaw was carried out for extraction of PBPs. After removal of cell debris by centrifugation at $15,000 \times \mathrm{g}$ for $30 \mathrm{~min}$, the supernatant was stored. The pellet was washed repeatedly with potassium phosphate $(50 \mathrm{mM})$ buffer till it became colorless. The pooled supernatant was considered as PBPs (partially purified). Absorbance spectra of PBPs were recorded by UV-Vis double beam spectrophotometer (U-2910, 2J1-0012, Hitachi, Tokyo, Japan) with a $1 \mathrm{~cm}$ path length. Phycoerythrin (PE) and PC absorb at 563 and $615 \mathrm{~nm}$, respectively.

\subsection{Extraction and partial purification of scytonemin.}

Photoprotective cyanobacterial pigment, scytonemin, were screened to determine the most suitable wavebands and the range of salinity $(\mathrm{NaCl})$ for their induction and biosynthesis. Extraction of scytonemin was done from the cyanobacterial samples in 1:1 (v/v) methanol:ethyl acetate by incubating them overnight at $4{ }^{\circ} \mathrm{C}$ followed by sonication (2011-Sonic, cycle 30\%, Power $40 \%)$ for $4 \mathrm{~min}$. This was followed by centrifugation $(10,000 \mathrm{~g})$ for $5 \mathrm{~min}$, and the resulting supernatants were evaporated through a vacuum evaporator at $38{ }^{\circ} \mathrm{C}$, and the remaining residues were re-dissolved in $500 \mu \mathrm{L}$ of $1: 1(\mathrm{v} / \mathrm{v})$ methanol:ethyl acetate. The samples were subjected to HPLC analyses after filtering them through $0.22 \mu \mathrm{m}$ pore-sized sterilized microcentrifuge syringe-driven filters. HPLC system (Waters 2998, Photodiode 
Array, pump L-7100, USA) which was equipped with a Licrospher RP 18 column and guard (5 $\mu \mathrm{m}$ packing; $250 \mathrm{~mm} \times 4 \mathrm{~mm}$ inside diameter) was used for purification of scytonemin. An auto-injector (Waters 717 plus autosampler) was used for injecting scytonemin samples (10 $\mu \mathrm{L}$ ) into the HPLC column. A flow rate of $1.0 \mathrm{~mL} \mathrm{~min}^{-1}$ was used for elution using the mobile phase of solvent A (ultra-pure water) and solvent B (acetonitrile-methanol-tetrahydrofuran, 75:15:10, v/v). The elution program of $30 \mathrm{~min}$ gradient was set with 0-15 min linear increase from $15 \%$ solvent $\mathrm{A}$ to $100 \%$ solvent $\mathrm{B}$, and $15-30 \mathrm{~min}$ at $100 \%$ solvent $\mathrm{B}$ with detection wavelength set at $376 \mathrm{~nm}$ and PDA scan wavelength ranging from 250-750 nm. Identification of scytonemin was made by its characteristic absorption maxima corresponding to the appropriate retention time (RT) [22]. Absorbance (O.D.) values at $386 \mathrm{~nm}$ were used for comparing the levels of scytonemin induction in different treatments.

\subsection{Statistical analysis.}

All the experiments were performed in triplicates. Results have been presented as mean values of three replicates. Statistical analyses were performed through a one-way analysis of variance. Once a significant difference was detected, the post hoc test Tukey test was done. For all tests, the level of significance was set at 0.05 .

\section{Results and Discussion}

\subsection{Effects of UVR and salinity on reactive oxygen species (ROS) generation.}

The generation of ROS was studied in the two cyanobacteria, namely Nostoc sp. strain HKAR-2 and Scytonema sp. under various combinations of PAR, UVR, and salinity by ROS sensitive probe DCFH-DA (Figure 1). The spectrofluorometry intensity data show that ROS generation increased significantly $(\mathrm{P}<0.05)$ in Nostoc sp. strain HKAR-2 reached up to 9.6 folds after $72 \mathrm{~h}$ in PAB as compared to control in $50 \mathrm{mM} \mathrm{NaCl}$ concentration. In PA and PAR the increase was of 7.1 and 6 folds, respectively (Figure 1). A similar trend was observed in Scytonema sp. also. Here, the increase was 10.5, 6.6, and 5.9 folds in PAB, PA, PAR, respectively (Figure 1) till $60 \mathrm{~h}$ of exposure in $50 \mathrm{mM} \mathrm{NaCl}$ concentration followed by a decrease in all light regimes. It was observed that in samples placed in PAR, ROS generation increased significantly with increasing duration of treatment and 100 and $200 \mathrm{mM}$ dose of $\mathrm{NaCl}$ up to $60 \mathrm{~h}$ of exposure in Nostoc sp. strain HKAR-2, but afterward, fluorescence signals in filaments started decreasing till $72 \mathrm{~h}$ which might be due to cell death because of high dose of salinity. Scytonema sp. showed a similar trend but fluorescence signals were less as compared to Nostoc sp. strain HKAR-2 in $200 \mathrm{mM}$ of salt dose (Figure 1). In all treated samples, fluorescence signal started appearing with increasing duration of exposure and increased continuously up to $48 \mathrm{~h}$ in $200 \mathrm{mM}$ of salt concentration. A similar pattern was observed in Nostoc sp. strain HKAR-2. Overall, in both the studied cyanobacteria, fluorescence signals in PA were higher than PAR. Fluorescence signals were more prominent in Nostoc sp. strain HKAR-2. However, in PAB, fluorescence signals started developing from $12 \mathrm{~h}$ and increased continuously with increasing duration of PAB exposure until $60 \mathrm{~h}$ of treatment. However, in Scytonema sp., lower fluorescence intensity was observed in comparison to Nostoc sp. strain HKAR-2 (Figure 1). 
$50 \mathrm{mM}$
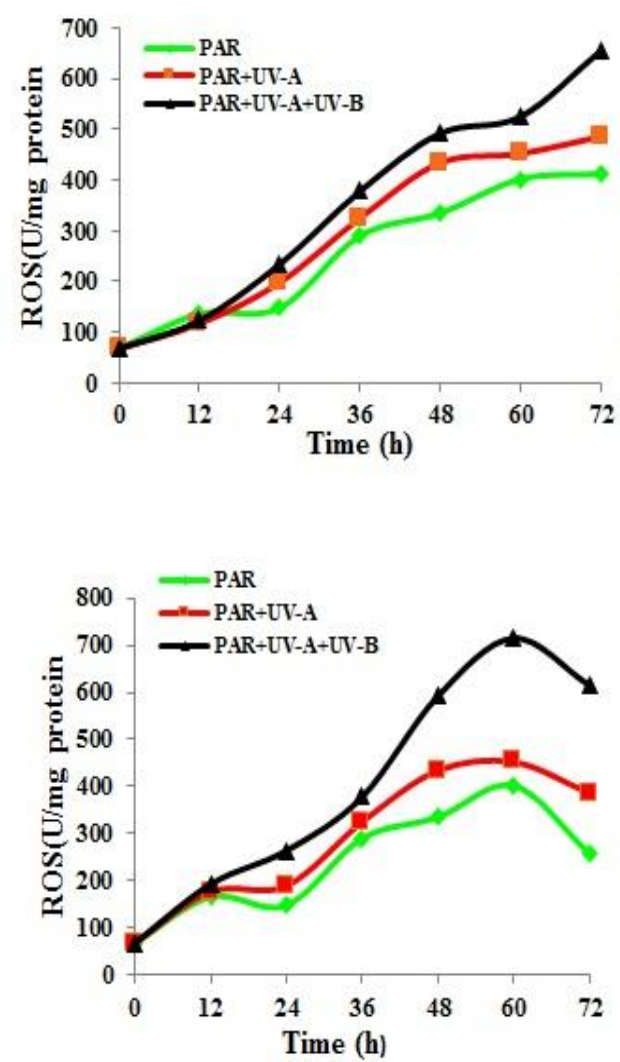

$100 \mathrm{mM}$
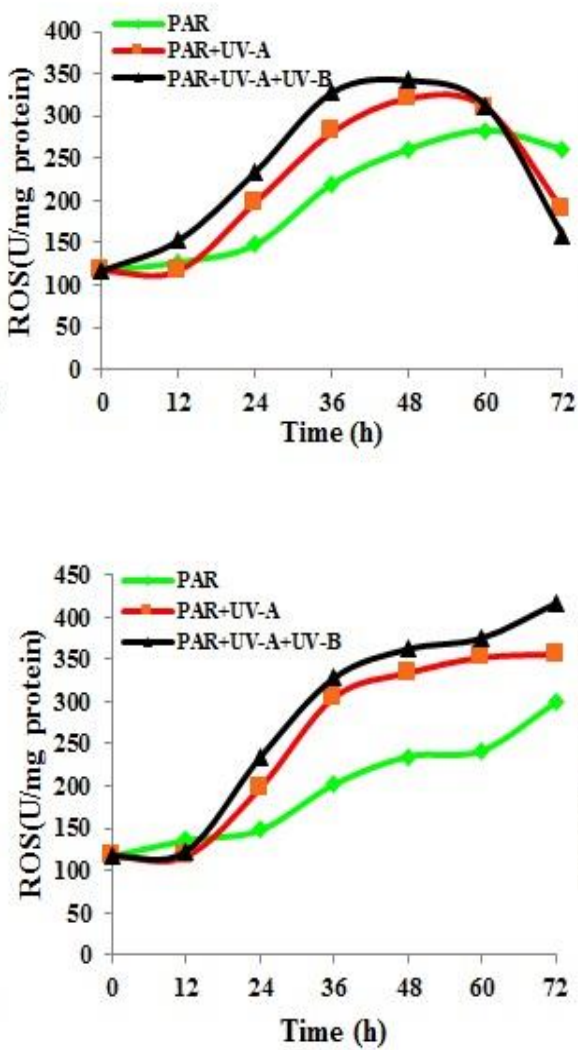

$200 \mathrm{mM}$
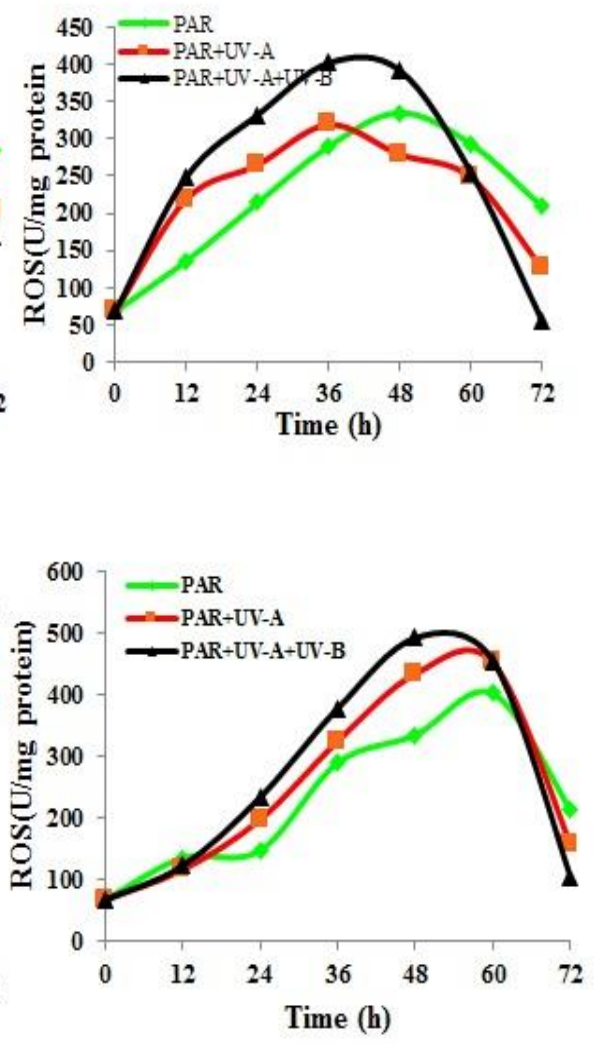

Figure 1. Reactive oxygen species generation in Nostoc sp. strain HKAR-2 (upper panel) and Scytonema sp. (lower panel) under photosynthetically active radiation (PAR), PAR+UV-A, and PAR+UV-A+UV-B in 50, 100, $200 \mathrm{mM}$ concentration of $\mathrm{NaCl}$, respectively. Results are expressed as means of three replicates.

\subsection{Effects of UVR and salinity on total protein content.}

Total protein content increased significantly $(\mathrm{P}<0.05)$ with increasing duration of PAR in $50 \mathrm{mM}$ salt concentration in both the cyanobacteria (Figure 2).
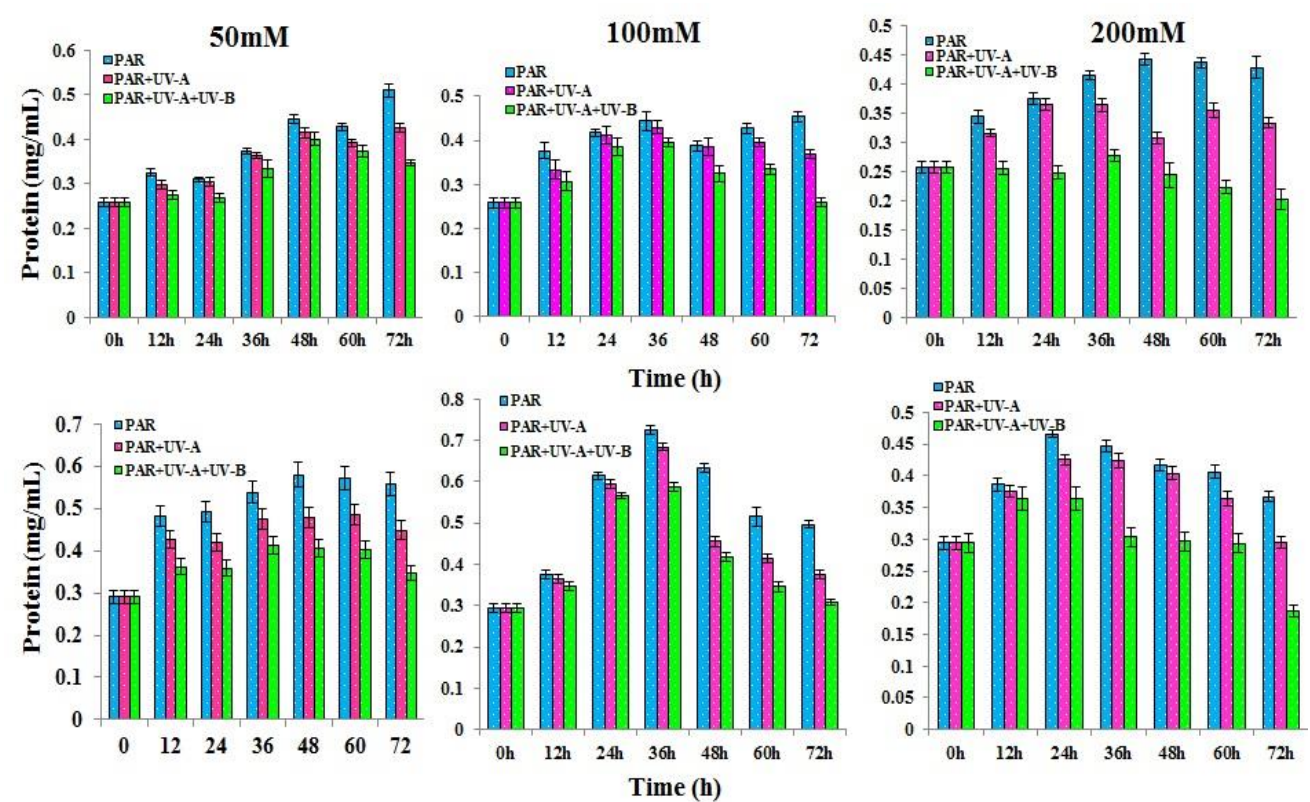

Figure 2. Effect of $\mathrm{NaCl}$ in combination with photosynthetically active radiation (PAR), PAR+UV-A, and

PAR+UV-A+UV-B on total protein contents of Nostoc sp. strain HKAR-2 (upper panel) and Scytonema sp.(lower panel) after varying duration of exposure. Results are expressed as means of three replicates. Vertical bars indicate the standard deviation of the means. 
However, an increase in protein content was maximum at 36 and $48 \mathrm{~h}$ of PA treatment in Nostoc sp. strain HKAR-2 and Scytonema sp. respectively in $50 \mathrm{mM}$ of $\mathrm{NaCl}$ treatment. In PAB, protein content increased till 36 and 48 h of treatment in Nostoc sp. strain HKAR-2 and Scytonema sp. respectively. In $100 \mathrm{mM}$ salt treatment, protein content increased till $36 \mathrm{~h}$ of $\mathrm{PAB}$ treatment in both the cyanobacteria (1.51 and 2 folds) followed by a significant decline $(\mathrm{P}<0.05)$ till $72 \mathrm{~h}$ ( 0.9 fold and 1 fold) (Figure 2). In the case of $200 \mathrm{mM}$ salt concentration, protein content increased with increasing $\mathrm{PA}$ and $\mathrm{PAB}$ treatment duration, followed by a decrease until $72 \mathrm{~h}$ of exposure.

\subsection{Effect of UVR and salinity on phycobiliproteins content.}

In $50 \mathrm{mM} \mathrm{NaCl}$, initially, there was a slight decrease in the absorption of PE (Figure 3a) after $12 \mathrm{~h}$ of exposure to PAR in Nostoc sp. strain HKAR-2 with no significant difference $(\mathrm{P}>0.05)$. The same absorption significantly $(\mathrm{P}<0.05)$ declined to about $45 \%$ between 48 and $72 \mathrm{~h}$ of PAR exposure.

PAR
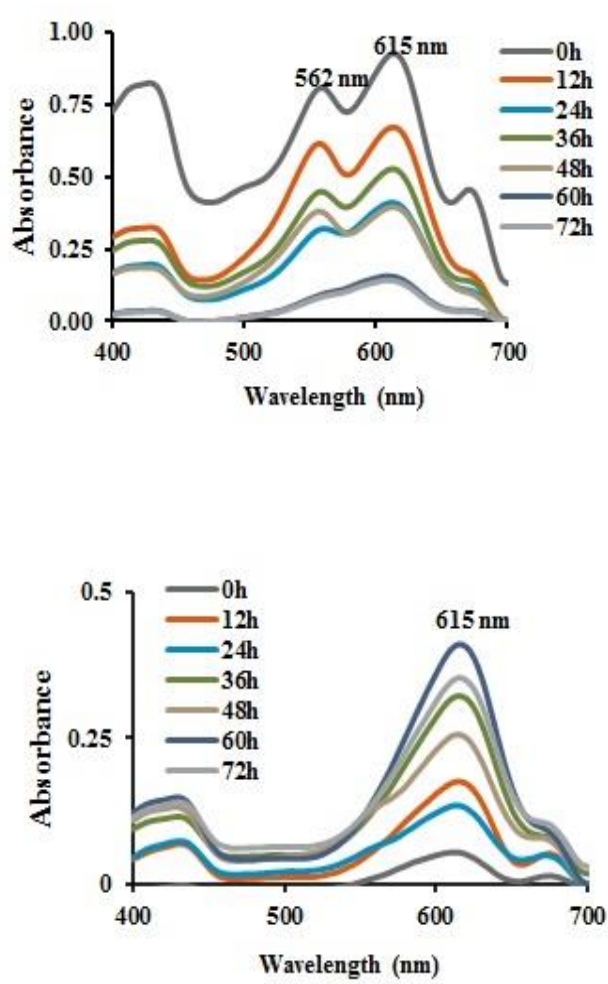

PAR+UV-A
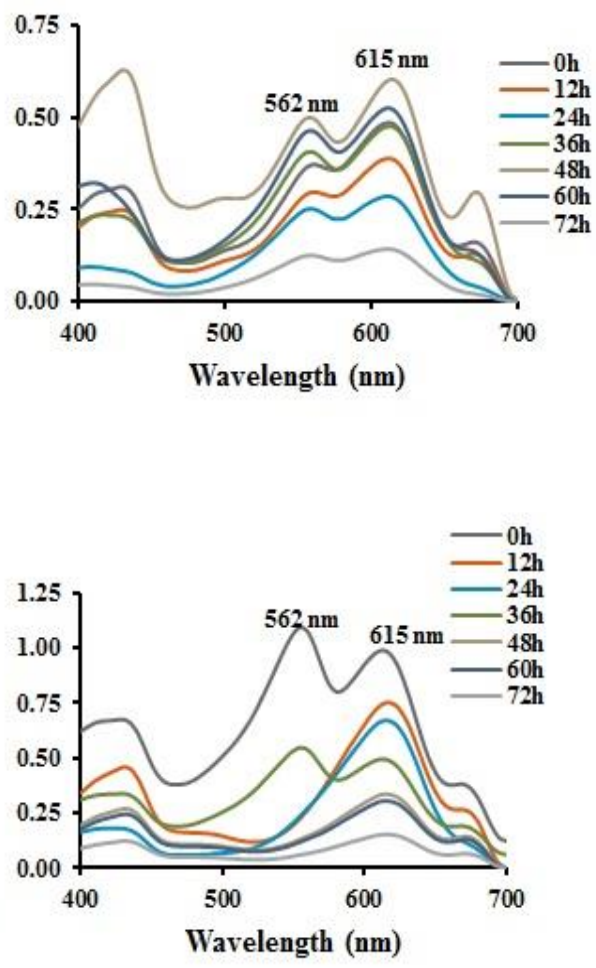

PAR+UV-A+UV-B

Figure 3a. Absorption spectra showing the effect of $50 \mathrm{mM} \mathrm{NaCl}$ in combination with photosynthetically active radiation (PAR), PAR+UV-A and PAR+UV-A+UV-B on phycobiliproteins profile of Nostoc sp. strain HKAR2 (upper panel) and Scytonema sp. (lower panel) after varying duration of exposure.

The absorption of $\mathrm{PE}$ declined up to $85 \%$ with significant $(\mathrm{P}<0.05)$ differences between 36 and $72 \mathrm{~h}$ of PA and PAB exposure. In Scytonema sp., the absorption of PE was slightly enhanced with no significant $(\mathrm{P}>0.05)$ difference up to 12-24 h PAR exposure; however, thereafter, it declined to $50 \%$ in $72 \mathrm{~h}$ exposure of PAR (Figure 3a). Upon $72 \mathrm{~h}$ of PAB exposure, more than $82 \%$ loss was recorded in $\mathrm{PE}$ with significant $(\mathrm{P}<0.05)$ differences. Similarly, exposure of $\mathrm{PA}$ and $\mathrm{PAB}$ showed a significant $(\mathrm{P}<0.05)$ reduction (up to $70 \%$ ) in absorption in PE. PC also significantly $(\mathrm{P}<0.05$ ) declined (up to $35 \%$ ) between 36 and $72 \mathrm{~h}$ exposure of PAR in Nostoc sp. strain HKAR-2. However, PC declined (up to 75\%) after $72 \mathrm{~h}$ of PA and PAB 
irradiation. In PAB exposure, PC declined slightly up to $12 \mathrm{~h}$ with no significant difference $(\mathrm{P}>0.05)$ thereafter, it declined $(85 \%)$ with a significant $(\mathrm{P}<0.05)$ difference up to $72 \mathrm{~h}$. The absorption of PC declined more (up to $45 \%$ ) after $72 \mathrm{~h}$ of PAR in Scytonema sp. as compared to Nostoc sp. strain HKAR-2 (Figure 3a). Similarly, upon PA and PAB exposure, there was a significant $(\mathrm{P}<0.05)$ decline in $\mathrm{PC}$ absorbance up to 92 and 82\%, respectively, in Scytonema sp. (Figure 3a).

In $100 \mathrm{mM} \mathrm{NaCl}$, initially, there was a slight decrease in the absorption of PE (Figure 3b) after $12 \mathrm{~h}$ of exposure to PAR in Nostoc sp. strain HKAR-2. The same absorption significantly $(\mathrm{P}<0.05)$ declined to about $55 \%$ between 48 and $72 \mathrm{~h}$ of PAR exposure. The absorption of $\mathrm{PE}$ declined up to $70 \%$ with significant differences $(\mathrm{P}<0.05)$ between 36 and 72 $\mathrm{h}$ of PA and PAB exposure. In Scytonema sp., the absorption of PE was slightly enhanced with no significant difference $(\mathrm{P}>0.05)$ up to $12-24 \mathrm{~h}$ PAR exposure; however, it declined to $75 \%$ in $72 \mathrm{~h}$ of PAR exposure (Figure $3 \mathrm{~b}$ ). Upon $72 \mathrm{~h}$ of PAB exposure, more than $75 \%$ significant loss was recorded in PE content. Similarly, exposure of PA and PAB showed a significant $(\mathrm{P}<0.05)$ reduction (up to $75 \%)$ in absorption in $\mathrm{PE}$. $\mathrm{PC}$ also declined significantly $(\mathrm{P}<0.05)$ (up to 70\%) between 36 and $72 \mathrm{~h}$ exposure of PAR in Nostoc sp. strain HKAR-2. However, $\mathrm{PC}$ declined (up to $90 \%$ ) after $72 \mathrm{~h}$ of PA and PAB irradiation. In PAB exposure, PC declined up to $12 \mathrm{~h}$ with no significant difference $(\mathrm{P}>0.05)$, after that, it declined significantly $(\mathrm{P}<0.05)$ (95\%) up to $72 \mathrm{~h}$. The PC content declined more (up to $70 \%$ ) after $72 \mathrm{~h}$ of PAR in Scytonema sp compared to Nostoc sp (Figure 3b). Similarly, upon PA and PAB exposure, there was a significant $(\mathrm{P}<0.05)$ decline in $\mathrm{PC}$ absorbance up to 88 and $78 \%$, respectively, in Scytonema sp.(Figure 3b).

PAR
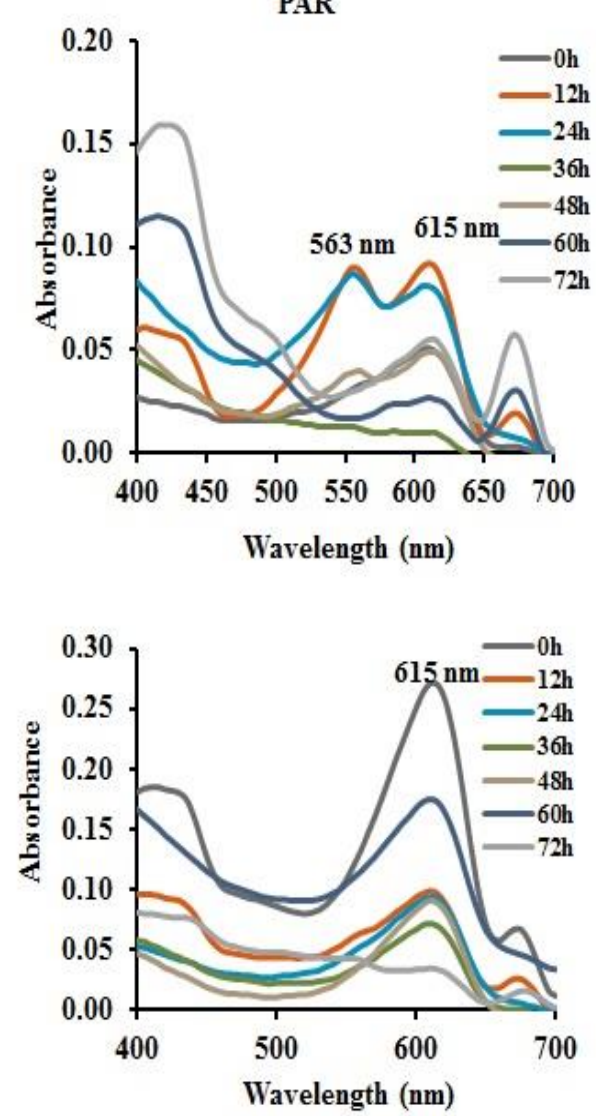

PAR+UV-A
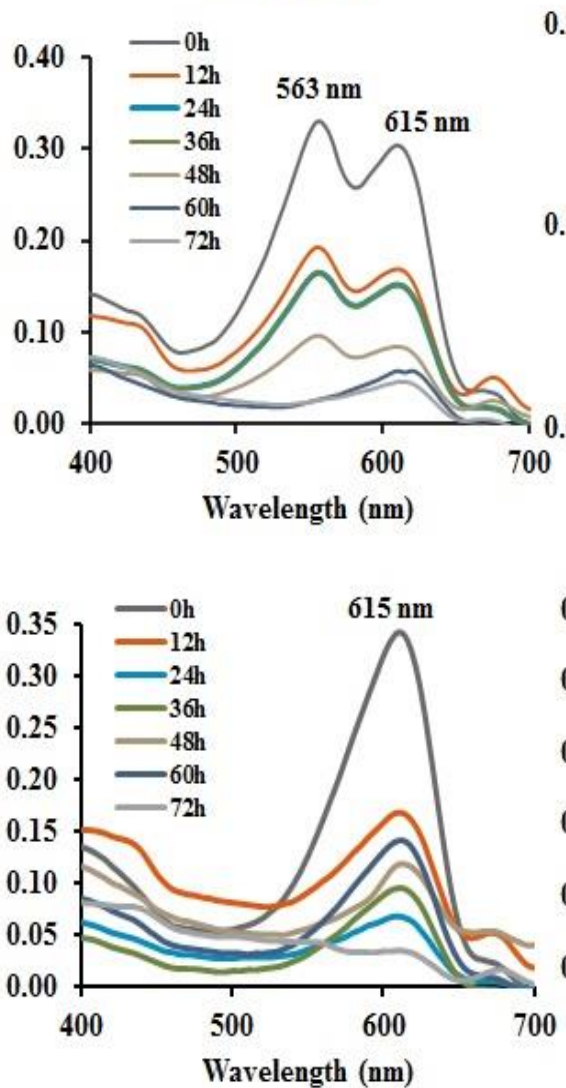

PAR+UV-A+UV-B
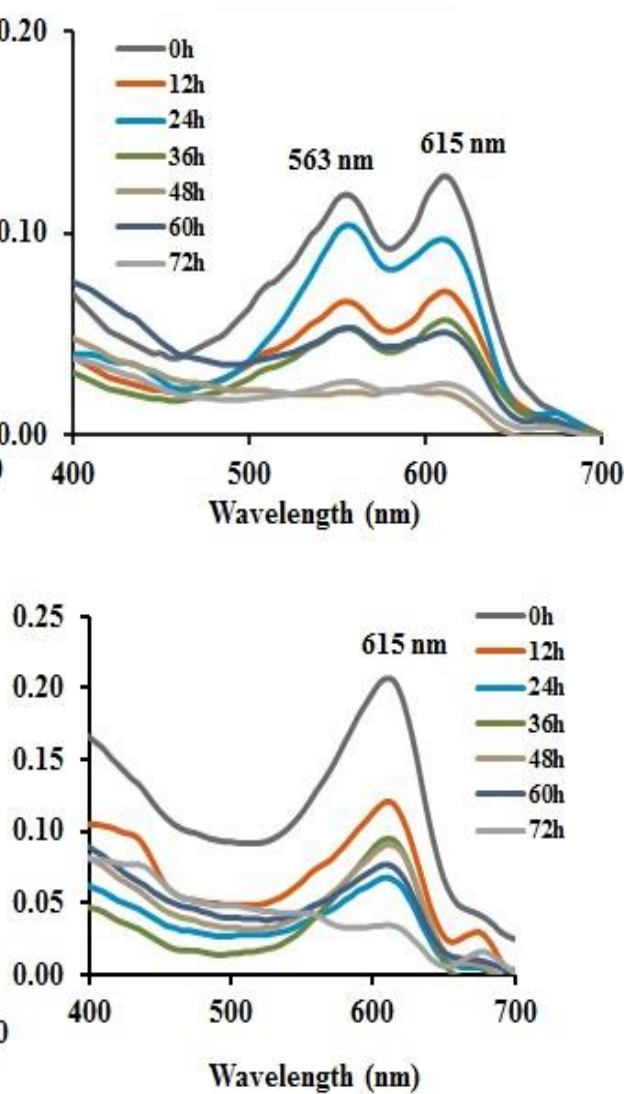

Figure 3b. Absorption spectra showing the effect of $100 \mathrm{mM} \mathrm{NaCl}$ in combination with photosynthetically active radiation (PAR), PAR+UV-A, and PAR+UV-A+UV-B on phycobiliproteins profile of Nostoc sp. strain HKAR-2 (Upper panel) and Scytonema sp. (lower panel) after varying duration of exposure. 
Initially, there was a slight increase in the absorption of PE (Figure 3c) after $12 \mathrm{~h}$ of exposure to PAR with $200 \mathrm{mM} \mathrm{NaCl}$ in Nostoc sp. strain HKAR-2. The same absorption significantly declined $(\mathrm{P}<0.05)$ to about $35 \%$ between 48 and $72 \mathrm{~h}$ of PAR exposure. The absorption of $\mathrm{PE}$ declined up to $85 \%$ with significant differences $(\mathrm{P}<0.05)$ between 36 and 72 $\mathrm{h}$ of PA and PAB exposure. In Scytonema sp., the absorption of PE slightly enhanced up to 24 h PAR exposure; however, thereafter, it declined to $70 \%$ till $72 \mathrm{~h}$ of PAR exposure (Figure 3c). Upon $72 \mathrm{~h}$ of PAB exposure, significant $(\mathrm{P}<0.05)$ loss of more than $92 \% \mathrm{PE}$ was recorded. Similarly, exposure of PA and PAB showed a significant $(\mathrm{P}<0.05)$ reduction (up to $90 \%$ ) in absorption in PE. PC also declined significantly ( $\mathrm{P}<0.05$ ) (up to $80 \%$ ) from 36 to $72 \mathrm{~h}$ exposure of PAR in Nostoc sp. strain HKAR-2 (Figure 3c). However, PC declined (up to 75\%) after 72 $\mathrm{h}$ of $\mathrm{PA}$ and $\mathrm{PAB}$ irradiation. In PAB exposure, $\mathrm{PC}$ declined slightly up to $12 \mathrm{~h}$ with no significant difference $(\mathrm{P}>0.05)$, but thereafter, it declined significantly $(\mathrm{P}<0.05)(75 \%)$ with a difference up to $72 \mathrm{~h}$. The absorption of PC declined up to $35 \%$ after $72 \mathrm{~h}$ of PAR treatment in Scytonema sp. which was more as compared to Nostoc sp. HKAR-2 (Figure 3c). Similarly, upon PA and PAB exposure, there was a significant $(\mathrm{P}<0.05)$ decline in $\mathrm{PC}$ absorbance, i.e., up to 77 and 69\%, respectively, in Scytonema sp.

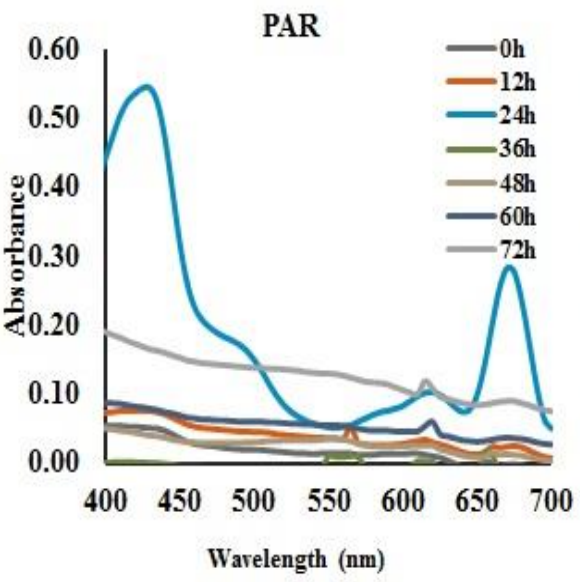

PAR+UV-A

PAR+UV-A+UV-B
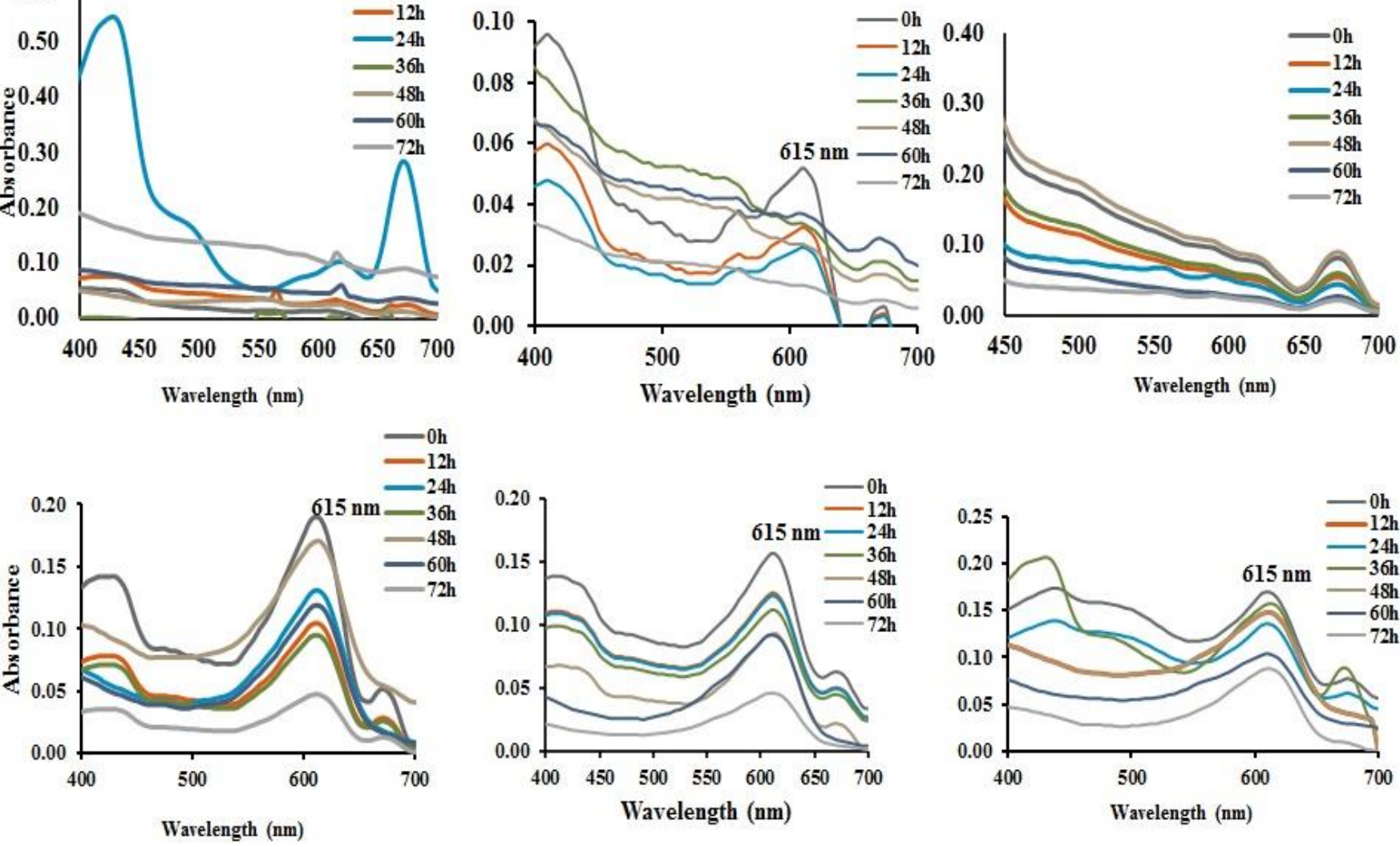

Figure 3c. Absorption spectra showing effect of $200 \mathrm{mM} \mathrm{NaCl}$ in combination with photosynthetically active radiation (PAR), PAR+UV-A and PAR+UV-A+UV-B on phycobiliproteins profile of Nostoc sp. strain HKAR-

2 (Upper panel) and Scytonema sp. (lower panel) after varying duration of exposure.

\subsection{Induction of scytonemin under combined stress of salinity and UVR.}

In the present study, attempts have been made to compare the scytonemin induction in the two cyanobacteria isolated from two different habitats under UVR and varying concentrations of $\mathrm{NaCl}(50,150$, and $200 \mathrm{mM})$. Exposure of the two strains to UVR and different doses of salinity resulted in scytonemin induction in Scytonema sp. only. No induction 
of scytonemin was reported in Nostoc sp. strain HKAR-2 in the given experimental conditions. Spectroscopic analysis and HPLC revealed the presence of a scytonemin $\left(\lambda_{\max }=386 \pm 2 \mathrm{~nm}\right)$ at the RT ranging between 2-4 min (Figure 4a, b).

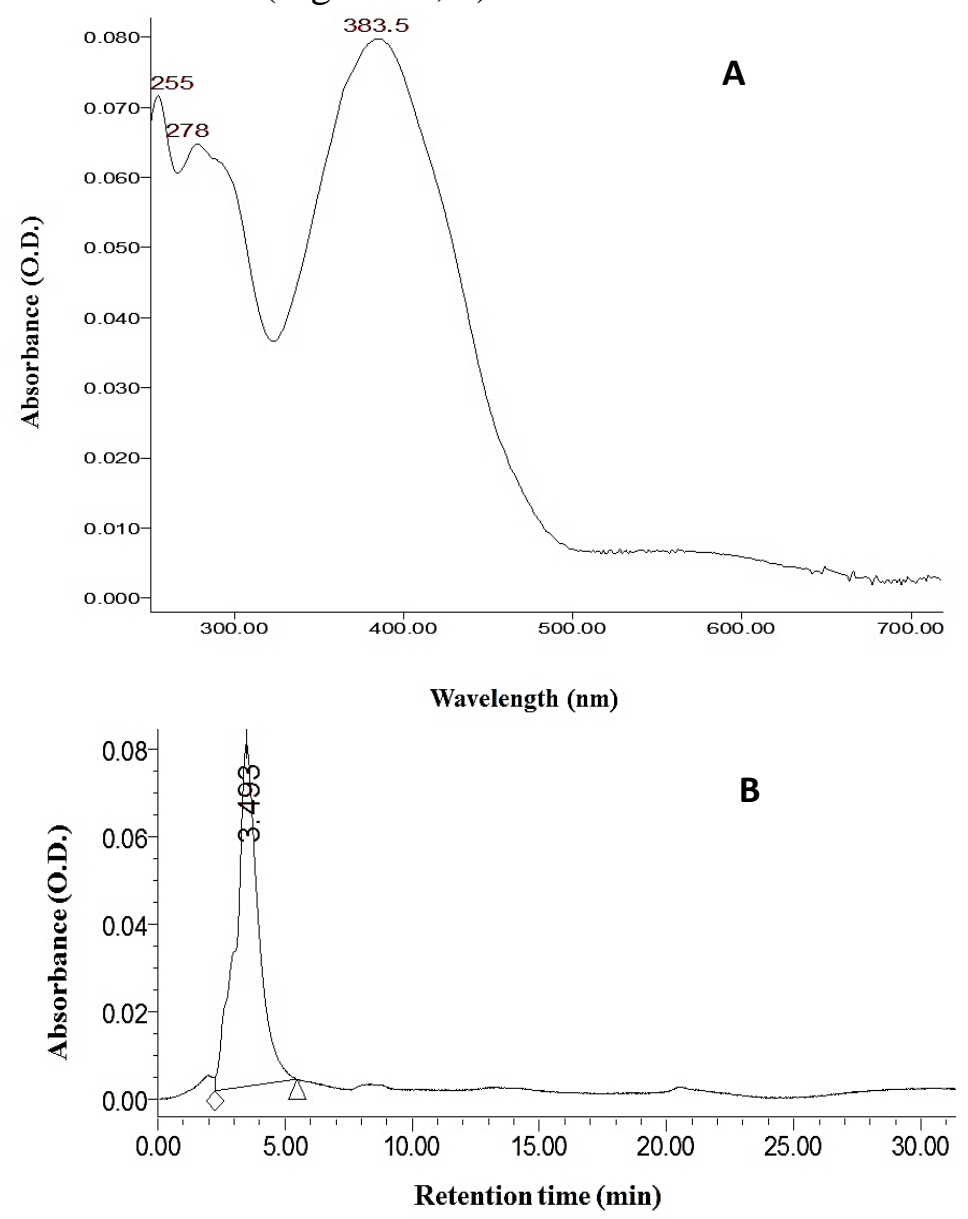

Figure 4. HPLC chromatogram of partially purified scytonemin (a) and their corresponding absorption spectrum (b) from Scytonema sp. at $36 \mathrm{~h}$ of PAR+UV-A+UV-B and $200 \mathrm{mM}$ concentration of $\mathrm{NaCl}$ treatment.

Induction of scytonemin was more pronounced under PAB treatment than PA or PAR alone. $\mathrm{NaCl}$ also affected induction of scytonemin in a concentration-dependent manner, which was found to be maximum after $60 \mathrm{~h}$ of PAB treated samples, having $200 \mathrm{mM}$ of $\mathrm{NaCl}$ (Figure 5a-c). UVR damages cyanobacterial cells by ROS generation, cell vitality impairment, lipid peroxidation, protein destruction, and DNA damage [61, 66]. From our results, it could be concluded that as ROS generation increased, scytonemin induction also increased significantly $(\mathrm{P}<0.05)$. Several reports have shown that the deleterious effects of UVR are mediated via the production of ROS [5, 7, 64], and here also it was observed that ROS generation increased upon exposure to stresses such as cumulative stress of salinity, UVR, and PAR. Under normal (unstressed) conditions, the ROS produced to serve as signaling molecules for various metabolic processes. However, their generation increases several folds under stress conditions and causes oxidative stress and damage [61-63]. Exposure of both the cyanobacteria to UVR and salinity led to the generation of ROS. As the duration of exposure increased, ROS generation also increased in Scytonema sp. as well as Nostoc sp. strain HKAR-2. On exposure to UV-B radiation, the production of ROS takes place by interfering with electron carriers of the photosynthetic pathway [61]. Interaction of endogenous chromophores with incident longwavelength UVR results in the initiation of UV-A mediated oxidation reactions to cellular DNA [67]. ROS attack biomolecules such as DNA, lipids, and proteins, resulting in their 
oxidation, which causes DNA damage, membrane damage, and protein modification. Hence, enhanced accumulation of ROS is very deleterious [61].
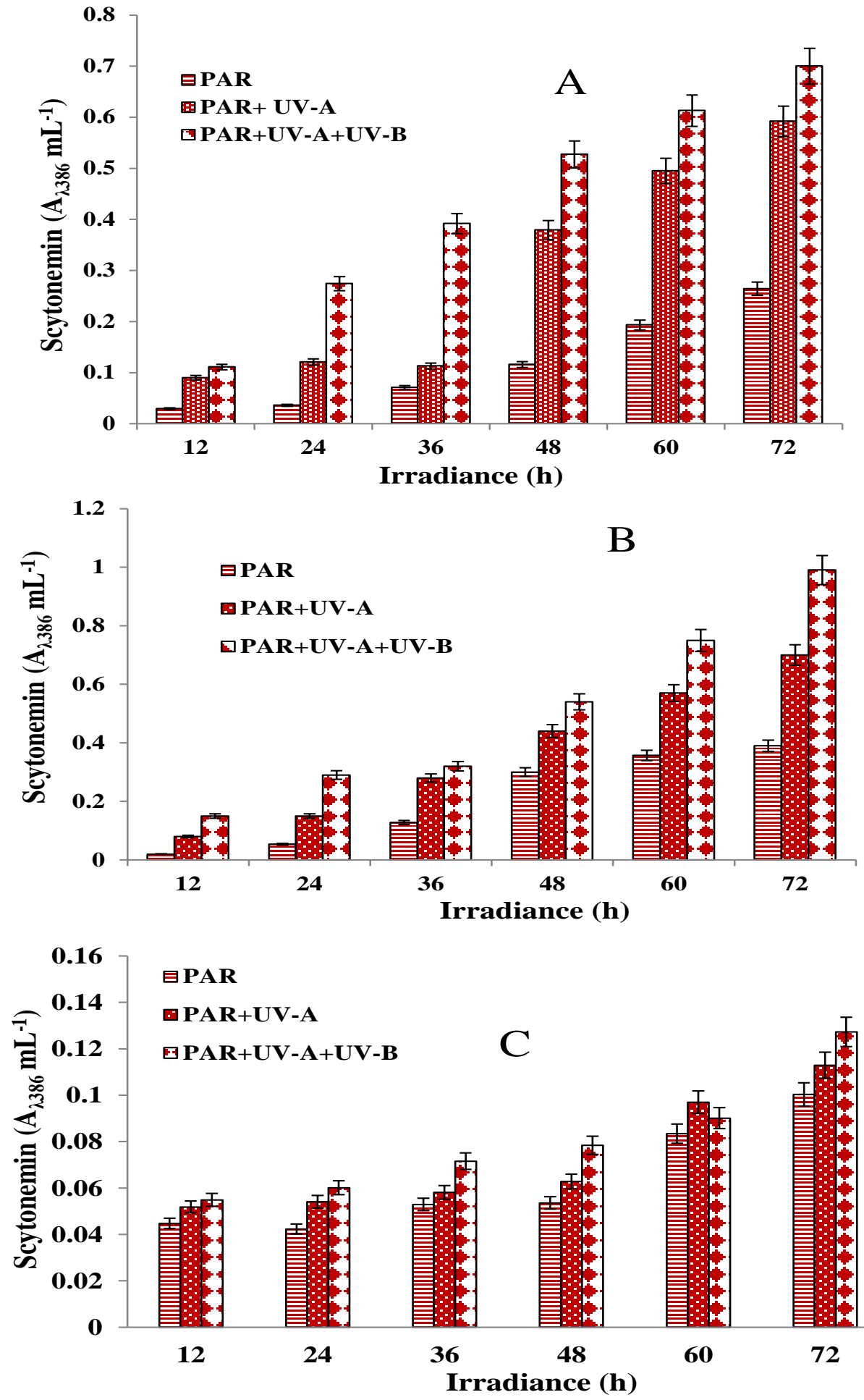

Figure 5. Induction of scytonemin during 12, 24, 36, 48, 60, and $72 \mathrm{~h}$ of exposure under photosynthetically active radiation (PAR), PAR+UV-A, and PAR+UV-A+UV-B exposure along with different concentrations of $\mathrm{NaCl}$ (a) $50 \mathrm{mM}$;(b) $100 \mathrm{mM}$;(c) $200 \mathrm{mM}$ in Scytonema sp. The error bars denote standard deviations of means (mean \pm S.D., $\mathrm{n}=3$ ).

Enhanced production of ROS can destroy D1 protein and affect PSII reaction center, electron transport, and photon absorption [68]. Thus, photosynthesis in the photosystem gets inhibited [69], leading to the destruction of photosynthetic apparatus, DNA, and enzymes [61]. ROS were generated in response to UVR and salinity stress in both the cyanobacteria and were found to have multifold induction in the organisms treated with PAB and $200 \mathrm{mM}$ salt 
compared to non-treated cultures. Production of ROS increased after PAR, PA, and PAB treatment, and maximum generation was observed in the cyanobacterial cultures treated with $200 \mathrm{mM}$ concentration of $\mathrm{NaCl}$.

Proteinaceous pigments may seem to be the primary target of UVR [10]. Strong inhibition of PC by UVR has also been reported [70]. The strong damaging effect of UVR and salinity on PC might be due to its localization on the thylakoid's outer surface membrane, which makes it more prone to stresses. In the combined stress of UVR and salinity, the effect was more pronounced on PC content [10]. Scytonemin was induced under UVR only in Scytonema sp. However, its biosynthesis has been reported in several strains of cyanobacteria in response to UVR, which is accumulated in extracellular sheath [18, 20, 22, 51]. The role of scytonemin in the survival and protection of cyanobacterial communities exposed to intense solar radiation is now well established. Strong UVR bleaches and photo-oxidizes all types of photosynthetic pigments [71]. Scytonemin biosynthesis was low in the cells exposed to PAR and PA, suggesting that PAR and PA alone were less effective in inducing scytonemin in Scytonema $\mathrm{sp}$. The increased biosynthesis of scytonemin under PAB exposure might be because of specific photoreceptors in the cells responsible for light (wavelength) dependent-biosynthesis of scytonemin. The effect of salinity was more pronounced after $12 \mathrm{~h}$ of treatment. PAB treatment along with $\mathrm{NaCl}(100$ and $200 \mathrm{mM})$ resulted in a significant increase $(\mathrm{P}<0.05)$ in scytonemin induction up to $72 \mathrm{~h}$ of treatment. Cultures having $200 \mathrm{mM} \mathrm{NaCl}$ showed multifold higher induction of scytonemin after $12,24,36,48,60$, and $72 \mathrm{~h}$ of exposure. Our results showed that $\mathrm{NaCl}$ exhibited concentration-dependent effects on scytonemin biosynthesis, and $200 \mathrm{mM}$ concentration of $\mathrm{NaCl}$ till $72 \mathrm{~h}$ of PAB treatment resulted in maximum scytonemin synthesis in the cyanobacterial cultures.

The tolerance in Scytonema sp. to UVR and salinity could be explained due to the presence of a thick sheath. The sheath is supposed to be a site of production and accumulation of scytonemin and extracellular polymeric substances. Thus, it probably helps reduce UV penetration inside the cells $[12-14,18,20,22]$. Nostoc sp. isolated from the hot-spring environment and Scytonema sp. from the rooftop showed the differential capability to survive under the prolonged UV stress and salinity due to different protection mechanisms. Biosynthesis of multipurpose secondary metabolite scytonemin in Scytonema sp. might help these organisms tolerate combined stress of UV and salt stress and other tolerance mechanisms. These cyanobacteria traits that help them survive against detrimental UVR need to be studied thoroughly for its possible utilization as strain useful for bioremediation of salt-rich soils.

\section{Conclusions}

Overall, it can be said that induction of scytonemin was more pronounced under $\mathrm{PAB}$ treatment than $\mathrm{PA}$ and PAR alone. $\mathrm{NaCl}$ affected scytonemin induction significantly in a concentration-dependent manner, and maximum scytonemin synthesis occurred after $60 \mathrm{~h}$ of PAB exposure along with $200 \mathrm{mM}$ of $\mathrm{NaCl}$ treatment. Scytonemin content increased to approximately 6, 2, and 9 folds till $72 \mathrm{~h}$ of PAB treated samples having 50, 100, and $200 \mathrm{mM}$ of $\mathrm{NaCl}$ in the culture medium, respectively. Protein content increased to 1.5-2 folds in both the cyanobacteria till $36 \mathrm{~h}$ of treatment, followed by a decrease on further treatment. PBPs profile reflected severe damage as a result of UVR and salt treatment. ROS formation increased many folds in response to the combined stress of salt and UVR. However, the generation of ROS was less in Scytonema sp. in comparison to hot spring isolate Nostoc sp. strain HKAR-2. These results suggest that in Scytonema sp. scytonemin induction plays an important role in 
withstanding UVR and salinity stress, and these cyanobacteria could be utilized for bioremediation of saline soils along with the production of value-added metabolite scytonemin.

\section{Funding}

Jainendra Pathak (09/013/0515/2013-EMR-I) and Deepak K. Singh (09/013(0612)/2015EMR-I) are thankful to the Council of Scientific and Industrial Research, New Delhi, India, for the financial support in the form of junior and senior research fellowships. Deepak Kumar (DST/INSPIRE Fellowship/2015/IF150191) is thankful to the Department of Science and Technology, Inspire Programme, New Delhi, India, for the fellowship. Haseen Ahmed is thankful to the University Grants Commission, New Delhi, India, for the financial support in the form of fellowship (UGC-JRF-21/12/2014 (ii) EU-V).

\section{Acknowledgments}

The authors are also thankful to the Interdisciplinary School of Life Sciences (ISLS), BHU, Varanasi, India, for providing access to the fluorescence spectroscopy facility.

\section{Conflicts of Interest}

The authors declare no conflict of interest.

\section{References}

1. Weatherhead, E.C.; Andersen, S.B. The search for signs of recovery of the ozone layer. Nature 2006, 441, 39-45, https://doi.org/10.1038/nature04746.

2. Pathak, J.; Ahmed, H.; Rajneesh; Singh, S.P.; Häder, D.-P.; Sinha, R.P. Effects of global climate change on cyanobacteria In Aquatic ecosystems in a changing climate, Häder, D.-P., Gao, K., Eds.: CRC Press, Boca Raton, 2018; pp. 45-61, https://doi.org/10.1201/9780429436130-4.

3. Vincent, W.F., Neale, P.J. Mechanisms of UV damage to aquatic organisms. In The effects of UV radiation on marine ecosystems, de Mora, S.J., Demers, S., Vernet, M., Eds.: Cambridge Univ. Press, Cambridge, 2000; pp. $149-176$.

4. Pathak, J.; Rajneesh; Singh, P.R.; Häder, D.P.; Sinha, R.P. UV-induced DNA damage and repair: A cyanobacterial perspective. Plant Gene 2019, 19, 100194, https://doi.org/10.1016/j.plgene.2019.100194.

5. Rajneesh; Pathak, J.; Richa; Häder, D.-P.; Sinha, R.P. Impacts of ultraviolet radiation on certain physiological and biochemical processes in cyanobacteria inhabiting diverse habitats. Environ. Exp. Bot. 2019, 161, 375387, https://doi.org/10.1016/j.envexpbot.2018.10.037.

6. Singh, V.; Pathak, J.; Pandey, A.; Kumar, D.; Ahmed, H.; Singh, D.K.; Richa ; Sinha, R.P. Mycosporine-like amino acids and antioxidative enzymes activity in Scytonema sp. under cumulative stress of UV radiation and salinity. J. Sci. Res. (BHU), 2020, 64, 207-216, https://doi.org/10.37398/JSR.2020.640130.

7. Ahmed, H.; Pathak, J.; Rajneesh; Sonkar, P.K.; Ganesan, V.; Häder, D.-P.; Sinha, R.P. Responses of a hot spring cyanobacterium under ultraviolet and photosynthetically active radiation: photosynthetic performance, antioxidative enzymes, mycosporine-like amino acid profiling and its antioxidative potentials. 3 Biotech 2021, 11, 10, https://doi.org/10.1007/s13205-020-02562-1.

8. Sinha, R.P.; Kumar, A.; Tyagi, M.B.; Häder, D.-P. Ultraviolet-B-induced destruction of phycobili proteins in cyanobacteria. Physiol. Mol. Biol. Plants 2005, 11, 313-319.

9. Wulff, A.; Mohlin, M.; Sundback, K. Intraspecific variation in the response of the cyanobacterium Nodularia spumigena to moderate UV-B radiation. Harmf. Algae 2007, 6, 388-399, https://doi.org/10.1016/j.hal.2006.11.003.

10. Kannaujiya, V.K.; Sinha, R.P. Impacts of rhythmic alteration of ultraviolet-B and photosynthetic active radiation on phycobiliproteins of hot spring cyanobacterium Nostoc sp. strain HKAR-2. Protoplasma 2017, 254, 423-433, https://doi.org/10.1007/s00709-016-0964-0. 
11. Pathak, J.; Rajneesh; Pandey, A.; Sinha, R.P. Effects of ultraviolet radiation (UV-B) and photosynthetically active radiation (PAR) on Nostoc sp. strain HKAR-11. J. Sci. Res. (BHU), 2019, 63, 127-140.

12. Pathak, J.; Richa; Rajneesh; Sonker, A.S.; Kannaujiya, V.K.; Sinha, R.P. Isolation and partial purification of scytonemin and mycosporine-like amino acids from biological crusts. J. Chem. Pharm. Res. 2015, 7, 362371.

13. Pathak, J.; Sonker, A.S.; Richa; Rajneesh; Kannaujiya, V.K.; Singh, V.; Ahmed, H.; Sinha, R.P. Screening and partial purification of photoprotective pigment scytonemin from cyanobacterial crusts dwelling on the historical monuments in and around Varanasi, India. Microbiol. Res. 2017, 8, 6559, https://doi.org/10.4081/mr.2017.6559.

14. Pathak, J.; Rajneesh; Ahmed, H.; Richa; Sinha, R.P. Metabolomic profiling of cyanobacterial UV-protective compounds. Curr. Metabolom. 2017, 5, 138-163, https://doi.org/10.2174/2213235x04666160829162640.

15. Pathak, J.; Ahmed, H.; Rajneesh, Singh, S.P.; Häder, D.-P.; Sinha, R.P. Genetic regulation of scytonemin and mycosporine-like amino acids (MAAs) biosynthesis in cyanobacteria. Plant Gene 2019, 17, 100172, https://doi.org/10.1016/j.plgene.2019.100172.

16. Pathak, J.; Ahmed, H.; Singh, P.R.; Singh, S.P.; Häder, D.-P.; Sinha, R.P. Mechanisms of photoprotection in cyanobacteria. In Cyanobacteria: From basic science to applications, Mishra, A.K., Tiwari, D.N., Rai, A.N., Eds.:Academic Press, 2019; pp. 145-171, https://doi.org/10.1016/B978-0-12-814667-5.00007-6.

17. Pathak, J.; Singh, D.K.; Singh, V.; Kumar, D.; Sinha, R.P. Natural sunscreens: Sources and mode of action. In Innovations in life scienceresearch, Sinha, R.P., Pandey, S., Ghoshal, N., Eds.: Nova Science Publishers, NewYork, USA, 2019; pp. 1-35.

18. Pathak, J.; Pandey, A.; Maurya, P.K.; Rajneesh; Sinha, R.P.; Singh. S.P. Cyanobacterial secondary metabolite scytonemin: A potential photoprotective and pharmaceutical compound. Proc. Natl. Acad. Sci. India Sect. B: Biol. Sci. 2020, 90, 467-481, https://doi.org/10.1007/s40011-019-01134-5.

19. D'Agostino, P.M.; Woodhouse, J.N.; Liew, H.T.; Sehnal, L.; Pickford, R.; Wong, H.L.; Burns, B.P.; Neilan, B.A. Bioinformatic, phylogenetic and chemical analysis of the UV-absorbing compounds scytonemin and mycosporine-like amino acids from the microbial mat communities of Shark Bay, Australia. Environ. Microbiol. 2019, 21, 702-715, https://doi.org/10.1111/1462-2920.14517.

20. Pandey, A.; Pathak, J.; Singh, D.K.; Ahmed, H.; Singh, V.; Kumar, D. Photoprotective role of UV-screening pigment scytonemin against UV-B-induced damages in the heterocyst-forming cyanobacterium Nostoc sp. strain HKAR-2. Braz. J. Bot. 2020, 43, 67-80, https://doi.org/10.1007/s40415-020-00589-5.

21. Singh, D.K.; Pathak, J.; Pandey, A.; Singh, V.; Ahmed, H.; Kumar, D.; Rajneesh; Sinha, R.P. Response of a rice-field cyanobacterium Anabaena sp. HKAR-7 upon exposure to ultraviolet-B radiation and ammonium chloride. Environ. Sustain. 2021, 4, 95-105, https://doi.org/10.1007/s42398-020-00146-6.

22. Rastogi, R.P.; Sinha, R.P.; Incharoensakdi, A. Partial characterization, UV-induction and photoprotective function of sunscreen pigment, scytonemin from Rivularia sp. HKAR-4. Chemosphere 2013, 93, 1874-1878, https://doi.org/10.1016/j.chemosphere.2013.06.057.

23. Kumari, N.; Pathak, J.; Dwivedy, A.K.; Sinha,R.P. Bioprospection of UV-screening compounds from lichens inhabiting the Indian state of Sikkim. Plant Arch. 2021, 21, 1168-1177, https://doi.org/10.51470/PLANTARCHIVES.2021.v21.no1.155.

24. Singh, N.; Dhar, D. Cyanobacterial reclamation of salt-affected soil. In Genetic engineering, biofertilisation, soil quality and organic farming. Sustainable agriculture reviews, Lichtfouse, E., Ed.: Springer, Dordrecht, The Netherlands, 2010; pp. 243-275.

25. Pathak, J.; Rajneesh; Maurya, P.; Singh, S.P.; Häder, D.-P.; Sinha, R.P. Cyanobacterial farming for environment friendly sustainable agriculture practices: Innovations and perspectives. Front. Environ. Sci. 2018, 6, 1-7, https://doi.org/10.3389/fenvs.2018.00007.

26. Rocha, F.; Lucas-Borja, M.E.; Pereira, P.; Muñoz-Rojas, M. Cyanobacteria as a nature-based biotechnological tool for restoring salt-affected soils. Agronomy 2020, 10, 1321, https://doi.org/10.3390/agronomy10091321.

27. Pade, N.; Hagemann, M. Salt acclimation of cyanobacteria and their application in biotechnology. Life 2015, 5, 25-49, https://doi.org/10.3390/life5010025.

28. Singh, R.N. Role of blue-green algae in nitrogen economy of Indian agriculture. Indian Council of Agricultural Research, New Delhi, 1961.

29. Singh, J.S.; Kumar, A.; Rai, A.N.; Singh, D.P. Cyanobacteria: A precious bio-resource in agriculture, ecosystem, and environmental sustainability. Front. Microbiol. 2016, 7, 529, https://doi.org/10.3389/fmicb.2016.00529. 
30. Mittler, R. Oxidative stress, antioxidants and stress tolerance. Trends Plant Sci. 2002, 7, 405-410, https://doi.org/10.1016/s1360-1385(02)02312-9.

31. Pathak, J.; Rajneesh; Ahmed, H.; Singh, D.K.; Singh, P.R.; Kumar, D.; Kannaujiya, VK.; Singh, S.P., Sinha, R.P. Oxidative stress and antioxidant defense in plants exposed to UV radiation. In Reactive oxygen, nitrogen and sulfur species in plants: production, metabolism, signaling and defense mechanisms, Hasanuzzaman, M., Fotopoulos, V., Nahar, K., Fujita, M., Eds.: John Wiley \& Sons Ltd.,West Sussex, UK, 2019; pp. 371-420, https://doi.org/10.1002/9781119468677.ch16.

32. Singh, S. P.; Montgomery, B.L. Salinity impacts photosynthetic pigmentation and cellular morphology changes by distinct mechanisms in Fremyella diplosiphon. Biochem. Biophys. Res. Commun. 2013, 433, 8489, https://doi.org/10.1016/j.bbrc.2013.02.060.

33. Singh, S.P.; Montgomery, B.L. Distinct salt-dependent effects impair Fremyella diplosiphon pigmentation and cellular shape. Plant Signal Behav. 2013, 8, e24713, https://doi.org/10.4161/psb.24713.

34. Jeanjean, R.; Matthijs, H.C.P.; Onana, B.; Havaux, M.; Joset, F. Exposure of the cyanobacterium Synechocystis PCC 6803 to salt stress induces concerted changes in respiration and photosynthesis. Plant Cell Physiol. 1993, 34, 1073-1079, https://doi.org/10.1093/oxfordjournals.pcp.a078521.

35. Huang, F.; Fulda, S.; Hagemann, M.; Norling, B. Proteomic screening of salt-stress-induced changes in plasma membranes of Synechocystis sp. strain PCC 6803. Proteomics 2006, 6, 910-920, https://doi.org/10.1002/pmic.200500114.

36. Pandhal, J.; Ow, S.Y.; Wright, P.C.; Biggs, C.A. Comparative proteomics study of salt tolerance between a non-sequenced extremely halotolerant cyanobacterium and its mildly halotolerant relative using in vivo metabolic labeling and in vitro isobaric labeling. J. Proteome Res. 2009, 8, 818-828, https://doi.org/10.1021/pr800283q.

37. Grossman, A.R.; Schaefer, M.; Chiang, G.G.; Collier, J.L. The phycobilisome, a light harvesting complex responsive to environmental conditions. Microbiol. Rev. 1993, 57, 725-749, https://doi.org/10.1128/mr.57.3.725-749.1993.

38. Schubert, H.; Hagemann, M. Salt effects on $77 \mathrm{~K}$ fluorescence and photosynthesis in the cyanobacterium Synechocystis sp. PCC 6803. FEMS Microbiol. Lett. 1990, 71, 169-172, https://doi.org/10.1111/j.15746968.1990.tb03817.x.

39. Schubert, H.; Fulda, S.; Hagemann, M. Effects of adaptation to different salt concentrations on photosynthesis and pigmentation of the cyanobacterium Synechocystis sp. PCC 6803. J. Plant Physiol. 1993, 142, 291-295, https://doi.org/10.1016/S0176-1617(11)80425-6.

40. Lu, C.; Torzilo, G.; Vonshak, A. Kinetic response of photosystem II photochemistry in cyanobacterium Spirulina platensis to high salinity is characterized by two distinct phases. Aust. J. Plant Physiol. 1999, l26, 283-292, https://doi.org/10.1071/PP98119.

41. Lu, C.; Vonshak, A. Effects of salinity stress on photosystem II function in cyanobacterial Spirulina platensis cells. Physiol. Plant. 2002, 114, 405-413, https://doi.org/10.1034/j.1399-3054.2002.1140310.x.

42. Verma, K.; Mohanty, P. Alterations in the structure of phycobilisomes of the cyanobacterium, Spirulina platensis in response to enhanced $\mathrm{Na}^{+}$level. World J. Microbiol. Biotechnol. 2000, 16, 795-798, https://doi.org/10.1023/A:1008975308664.

43. Kumar, D.; Kannaujiya, V.K.; Richa; Pathak, J.; Sundaram, S.; Sinha, R.P. Composition and functional property of photosynthetic pigments under circadian rhythm in the cyanobacterium Spirulina platensis. Protoplasma 2018, 255, 885-898, https://doi.org/10.1007/s00709-017-1195-8.

44. Sinha, R.P.; Lebert, M.; Kumar, A.; Kumar, H.D.; Häder, D.-P. Disintegration of phycobilisomes in a rice field cyanobacterium Nostoc sp. following UV irradiation. Biochem. Mol. Biol. Int. 1995, 37, 697-706.

45. Aráoz, R.; Häder, D.-P. Ultraviolet radiation induces both degradation and synthesis of phycobilisomes in Nostoc sp.: A spectroscopic and biochemical approach. FEMS Microbiol. Ecol. 1997, 23, 301-313.

46. Dillon, J.G.; Tatsumi, C.M.; Tandingan, P.G.; Castenholz, R.W. Effect of environmental factors on the synthesis of scytonemin, a UV screening pigment, in a cyanobacterium (Chroococcidiopsis sp). Arch. Microbiol. 2002, 177, 322-331, https://doi.org/10.1007/s00203-001-0395-x.

47. Rath, J.; Mandal, S.; Adhikary, S.P. Salinity induced synthesis of UV-screening compound scytonemin in the cyanobacterium Lyngbya aestuarii. J. Photochem. Photobiol. B: Biol. 2012, 115, 5-8, https://doi.org/10.1016/j.jphotobiol.2012.06.002.

48. Kang, M.R.; Jo, S.A.; Lee, H.; Yoon, Y.D.; Kwon, J.-H.; Yang, J.-W.; Choi, B.J.; Park, K.H.; Lee, M.Y.; Lee, C.W.; Lee, K.-R.; Kang, J.S. Inhibition of skin inflammation by scytonemin, an ultraviolet sunscreen pigment. Mar. Drugs 2020, 18, 300, https://doi.org/10.3390/md18060300. 
49. Mandal, M.K.; Chanu, N.K.; Chaurasia, N. Cyanobacterial pigments and their fluorescence characteristics: applications in research and industry. In Advances in cyanobacterial biology, Singh, P., Kumar,A., Singh,V.K., Shrivistava,A., Eds.: Academic Press, 2020; 55-72, https://doi.org/10.1016/B978-0-12-8193112.00005-X.

50. Gao, X.; Jing, X.; Liu, X.; Lindblad, P. Biotechnological production of the sunscreen pigmentscytonemin in cyanobacteria: Progress and strategy. Mar. Drugs 2021, 19, 129, https://doi.org/10.3390/md19030129.

51. Rastogi, R.P.; Incharoensakdi, A. Characterization of UV-screening compounds, mycosporine-like amino acids, and scytonemin in the cyanobacterium Lyngbya sp. CU2555. FEMS Microbiol. Ecol. 2014, 87, 244256, https://doi.org/10.1111/1574-6941.12220.

52. Orellana, G.; Gómez-Silva, B.; Urrutia, M.; Galetović, A. UV-A irradiation increases scytonemin biosynthesis in cyanobacteria inhabiting halites at Salar Grande, Atacama desert. Microorganisms 2020, 8, 1690, https://doi.org/10.3390/microorganisms8111690.

53. Brenowitz, S.; Castenholz, R.W. Long-term effects of UV and visible irradiance on natural populations of a scytonemin-containing cyanobacterium (Calothrix sp.). FEMS Microbiol. Ecol. 1997, 24, 343352,https://doi.org/10.1111/j.1574-6941.1997.tb00451.x.

54. Garcia-Pichel, F.; Castenholz, R.W. Characterization and biological implication of scytonemin, a cyanobacterial sheath pigment. J. Phycol. 1991, 27, 395-409, https://doi.org/10.1111/j.00223646.1991.00395.x.

55. Sinha, R.P.; Pathak, J.; Rajneesh; Ahmed, H.; Pandey, A.; Singh, P.R.; Mishra, S.; Häder, D.-P. Cyanobacterial photoprotective compounds: Characterization and utilization in human welfare. In Natural bioactive compounds: Technological advancements, Sinha, R.P., Häder, D.-P., Eds.: Academic Press, 2021; pp. 83-114,https://doi.org/10.1016/B978-0-12-820655-3.00005-7.

56. Rastogi, R.P.; Kumari, S.; Han, T.; Sinha, R.P. Molecular characterization of hot spring cyanobacteria and evaluation of their photoprotective compounds. Can. J. Microbiol. 2012, 58, 719-727, https://doi.org/10.1139/w2012-044.

57. Desikachary, T.Y. Cyanophyta. Indian Council of Agricultural Research, New Delhi, 1959.

58. Komárek, J.; Kastovsky, J.; Mares, J.; Johansen, J.R. Taxonomic classification of cyanoprokaryotes (cyanobacterial genera) 2014, using a polyphasic approach. Preslia 2014, 86, 295-335.

59. Sinha, R.P.; Kumar, H.D.; Kumar, A.; Häder, D.-P. Effects of UV-B irradiation on growth, survival, pigmentation and nitrogen metabolism enzymes in cyanobacteria. Acta Protozool. 1995, 34, 187-192.

60. Rippka, R.; Deruelles, J.; Waterbury, J.B.; Herdman, M.; Stanier, R.Y. Generic assignments, strain histories and properties of pure cultures of cyanobacteria. Microbiology 1979, 111, 1-61, https://doi.org/10.1099/00221287-111-1-1.

61. He, Y.Y.; Häder, D.-P. Reactive oxygen species and UV-B: effect on cyanobacteria. Photochem. Photobiol. Sci. 2002, 1, 729-736, https://doi.org/10.1039/b110365m.

62. He, Y.Y.; Häder, D.-P. Involvement of reactive oxygen species in the UV-B damage to the cyanobacterium Anabaena sp. J. Photochem. Photobiol. B: Biol. 2002, 66, 73-80, https://doi.org/10.1016/s10111344(01)00278-0.

63. He, Y.Y.; Häder, D.-P. UV-B-induced formation of reactive oxygen species and oxidative damage of the cyanobacterium Anabaena sp.: protective effects of ascorbic acid and N-acetyl-L-cysteine. J. Photochem. Photobiol. B: Biol. 2002, 66, 115-124, https://doi.org/10.1016/s1011-1344(02)00231-2.

64. Rajneesh; Pathak, J.; Chatterjee, A.; Singh, S.P.; Sinha, R.P. Detection of reactive oxygen species (ROS) in cyanobacteria using the oxidant-sensing probe 2', 7'-dichlorodihydrofluorescein diacetate (DCFH-DA). Bioprotocol 2017, 7, e2545, https://doi.org/10.21769/BioProtoc.2545.

65. Lowry, O.H.; Rosebrough, N.J.; Farr, A.L.; Randall, R.J. Protein measurement with the Folin phenol reagent. J. Biol. Chem. 1951, 193, 265-275.

66. Wang, G.; Deng, S.; Liu, J.; Ye, C.; Zhou, X.; Chen, L. Cell damage caused by ultraviolet B radiation in the desert cyanobacterium Phormidium tenue and its recovery process. Ecotoxicol. Environ. Safety 2017, 144, 315-320, https://doi.org/10.1016/j.ecoenv.2017.06.024.

67. Cadet, J.; Sage, E.; Douki, T. Ultraviolet radiation-mediated damage to cellular DNA. Mutat. Res. 2005, 571, 3-17, https://doi.org/10.1016/j.mrfmmm.2004.09.012.

68. Xia, J.; Li, Y.J.; Zou, D. Effects of salinity stress on PSII in Ulva lactuca as probed by chlorophyll fluorescence measurements. Aquat. Bot. 2004, 80, 129-137, https://doi.org/10.1016/j.aquabot.2004.07.006. 
69. Xiong, F. Evidence that UV-B tolerance of the photosynthetic apparatus in microalgae is related to the D1turnover mediated repair cycle in vivo. J. Plant Physiol. 2001, 158, 285-294, https://doi.org/10.1078/01761617-00306.

70. Marwood, C.A.; Greenberg, B.M. Effect of supplementary UV-B radiation on chlorophyll synthesis and accumulation of photosystems during chloroplast development in Spirodela oligorrhiza. Photochem. Photobiol. 1996, 64, 664-670, https://doi.org/10.1111/j.1751-1097.1996.tb03121.x.

71. Häder, D.-P.; Häder, M.A. Effects of solar radiation on mobility in: Stentor coeruleus. Photochem. Photobiol. 1991, 54, 423-428, https://doi.org/10.1111/j.1751-1097.1991.tb02036.x. 